\title{
Danshensu protects vascular endothelia in a rat model of hyperhomocysteinemia
}

\author{
Rui-xue YANG ${ }^{1}$, Shan-ying HUANG ${ }^{1}$, Fang-fang YAN ${ }^{1}$, Xiao-ting LU $^{1}$, Yi-fan XING ${ }^{1}$, Yan LIU ${ }^{1}$, Yun-fang LIU ${ }^{2, *}$, Yu-xia ZHAO ${ }^{1, *}$ \\ ${ }^{1}$ The Key Laboratory of Cardiovascular Remodeling and Function Research, Chinese Ministry of Education and Chinese Ministry of \\ Public Health, Shandong University, Ji-nan 250012, China; ${ }^{2}$ Department of Diagnosis, Medical School, Shandong University, Ji-nan \\ 250012, China
}

\begin{abstract}
Aim: To examine whether danshensu could protect vascular endothelia in a rat model of hyperhomocysteinemia.
Methods: The model was established by feeding rats with a methionine-rich diet $\left(1 \mathrm{~g} \cdot \mathrm{kg}^{-1} \cdot \mathrm{d}^{-1}\right)$ for 3 months. Immediately following the discontinuation of methionine-rich diet, rats were treated with danshensu $\left(67.5 \mathrm{mg} \cdot \mathrm{kg}^{-1} \cdot \mathrm{d}^{-1}\right.$, po) or saline for 3 additional months. One group of rats receiving vitamin mixture (folic acid, vitamin B12 and vitamin B6) was included as a positive control. One group of rats not exposed to methionine-rich diet was also included as a blank control. The expression of tumor necrosis factor-alpha (TNF-alpha) and intercellular adhesion molecule-1 (ICAM-1) protein in the descending aorta was examined using immunohistochemistry and Western blot. Homocysteine and blood concentration of endothelin and nitric oxide (NO) was also examined.

Results: Methionine-rich diet resulted in accumulation of "foam cells", up-regulated expression of TNF-alpha and ICAM-1 in the descending aorta, and significantly increased serum homocysteine. Plasma endothelin concentration was significantly increased; NO was decreased. Danshensu treatment, either simultaneous to methionine-rich diet or afterwards, attenuated the above mentioned changes.

Conclusion: Chronic treatment with danshensu could prevent/attenuate the formation of atherosclerosis. Potential mechanisms include inhibited expression of representative proinflammatory cytokines and adhesion molecules in arterial endothelia. Changes in homocysteine and circulating molecules that control vascular contraction/relaxation via endothelial cells (eg, endothelin and NO) were also implicated.
\end{abstract}

Keywords: hyperhomocysteinemia; danshensu; endothelin; nitric oxide; tumor necrosis factor-alpha; intercellular adhesion molecule-1

Acta Pharmacologica Sinica (2010) 31: 1395-1400; doi: 10.1038/aps.2010.167; published online 27 Sep 2010

\section{Introduction}

Hyperhomocysteinemia (elevated circulating level of homocysteine) often occurs in patients with one or more defective genes (eg, methylenetetrahydrofolate reductase) that control the breakdown of homocysteine ${ }^{[1]}$, and is an independent risk factor for atherosclerosis ${ }^{[2]}$. Deficiency of folate, vitamin B6 and B12 could also result in hyperhomocysteinemia ${ }^{[3]}$. High level of homocysteine damages endothelial cells in vasculature via increased formation of reactive oxygen species (ROS) and inflammation, and therefore increases the likelihood to develop heart attack and stroke ${ }^{[4-7]}$. Hyperhomocysteinemia also promotes LDL oxidation and internalization by macrophages, which in turn is the initial step of atherosclerosis ${ }^{[8]}$.

\footnotetext{
* To whom correspondence should be addressed.

E-mail xuel@sdu.edu.cn (Yu-xia ZHAO);

liuyf@sdu.edu.cn (Yun-fang LIU)

Received 2010-05-08 Accepted 2010-08-19
}

Supplementation of folate, vitamin B6 and B12 could reduce the level of homocysteine in patients with hyperhomocysteinemia $^{[9]}$, but do not affect the process of atherosclerosis directly $^{[10]}$. As a result, the benefit is limited ${ }^{[11-13]}$.

Radix salviae miltiorrhizae (commonly known as "Danshen") has been used by practitioners of the Traditional Chinese Medicine for decades in the treatment of a variety of cardiovascular diseases. Danshensu [3-(3,4-dihydroxyphenyl)-2-hydroxy-propionic acid], a major active component of Danshen, could improve microcirculation, suppress the formation of ROS, inhibit platelet adhesion and aggregation, and protect myocardium against ischemia ${ }^{[14-16]}$. Danshensu could also protect endothelial cells against injury induced by hyperhomocysteinemia ${ }^{[17]}$ or inflammation ${ }^{[18]}$.

Effects of danshensu on homocysteine, TNF-alpha, ICAM-1, endothelin and NO have been reported by many labs. For example, Cao and colleagues ${ }^{[19]}$ reported decreased homocysteine level in rats in response to danshensu treatment. 
Ding et $a l^{[20]}$ showed that danshensu inhibits the expression of ICAM-1 induced by TNF-alpha in endothelial cells. In addition, danshensu also inhibits proliferation of vascular smooth muscle cells induced by elevated NO level and decreased ET- $1^{[21]}$. In the current study, we examined potential effects of danshensu on the formation of atherosclerosis in a rat model of hyperhomocysteinemia. Signaling molecules that control vascular contraction/relaxation, and representative proinflammatory cytokines and ICAM- 1 were also investigated.

\section{Materials and methods Animal treatment}

Animal experiments were conducted in compliance with the Animal Management Rules of the Ministry of Health of the People's Republic of China (Document \#55, 2001) and were approved by the Animal Care and Use Committee of Shandong University. Wistar rats were purchased from Shandong Academy of Medical Sciences, and housed individually in stainless cages at $24{ }^{\circ} \mathrm{C}$ with a 12-h light-dark cycle. Rats $(200 \mathrm{~g})$ received a methionine-rich diet (provided by Dr Weidong ZHANG, Shandong Academy of Medical Sciences) for 3 months. Intake of methionine-rich diet was monitored daily and adjusted to a level of $1 \mathrm{~g}$ methionine per day per $\mathrm{kg}$ body weight. Access to water was unrestricted. At the end of the 3-month methionine-rich diet, rats received daily treatment of danshensu $\left(67.5 \mathrm{mg} \cdot \mathrm{kg}^{-1} \cdot \mathrm{d}^{-1}\right.$, po; (Ang Sheng Shaanxi Biomedical Technology, Xi'an, China), a vitamin mixture (folic acid $0.45 \mathrm{mg} \cdot \mathrm{kg}^{-1} \cdot \mathrm{d}^{-1}$, vitamin B12 $6.75 \mu \mathrm{g} \cdot \mathrm{kg}^{-1} \cdot \mathrm{d}^{-1}$, vitamin B6 2.7 $\mathrm{mg} \cdot \mathrm{kg}^{-1} \cdot \mathrm{d}^{-1} ; p o$ ), or saline for another 3 months before sacrifice. Each group consisted of 5 male and 5 female rats. An additional "prevention" group received danshensu $\left(67.5 \mathrm{mg} \cdot \mathrm{kg}^{-1-}\right.$ $\cdot \mathrm{d}^{-1}, \mathrm{po}$ ) during the 3-month period of methionine-rich diet. Data collected from this group were compared to a "model" group that was sacrificed immediately after the 3-month methionine-rich diet. A group of rats not exposed to methioninerich diet was also included as a blank control.

At the end of the experiments, rats were sacrificed with chloral hydrate $(0.36 \mathrm{~g} / \mathrm{kg})$. Trunk blood was collected; blood samples were stored at $-80^{\circ} \mathrm{C}$. Segments of descending aorta were collected for Western blot analysis, or fixed with $4 \%$ paraformaldehyde and processed for immunohistochemical analysis or routine $H \& E$ staining.

\section{ICAM-1 and TNF-alpha expression}

The expression of ICAM-1 and TNF-alpha was examined with a 3-step streptavidin-biotin immunoperoxidase method ${ }^{[22]}$. Tissue sections $(5 \mu \mathrm{m})$ were deparaffinized and rehydrated, and then heated in a microwave oven for $10 \mathrm{~min}$ to enhance antigen retrieval. Slides were incubated with $3 \% \mathrm{H}_{2} \mathrm{O}_{2}$ for $10 \mathrm{~min}$ to quench endogenous peroxidase, and then blocked with $5 \%$ normal goat serum for $20 \mathrm{~min}$. Tissue sections were incubated with a rabbit anti-rat ICAM-1 or rabbit anti-rat TNF-alpha antibody (1:200 dilution; Bosider, Wuhan, China) for $2 \mathrm{~h}$ in a moisture chamber at $37^{\circ} \mathrm{C}$. After extensive washing, sections were incubated with biotinylated goat antirabbit IgG (1:200 dilution) and avidin for $30 \mathrm{~min}$ at $37^{\circ} \mathrm{C}$, and developed using a diaminobenzidine method. Sections were counterstained with hematoxylin for $15 \mathrm{~s}$. For blank controls, primary antibody was omitted. Sections were examined under a microscope for positively stained cells (brown or yellow). Data were analyzed with CMIAS series of true color multi-functional pathological image analysis system (Beijing University of Aeronautics and Astronautics, Beijing, China). The mean optical density of positively stained cells from 10 randomly selected fields $(\times 400)$ was calculated, and used to estimate the expression of ICAM-1 and TNF-alpha.

\section{Western blot analysis}

The descending aorta was homogenized and then digested with a lysis buffer, and centrifuged at $13000 \times g$ for $15 \mathrm{~min}$ at $4{ }^{\circ} \mathrm{C}$. Protein concentration in the supernatant was measured with a BCA method (Pierce Corporation, Tempe, AZ, US). Samples (20 $\mu$ g protein) were separated with 10\% SDS-PAGE, and transferred to a polyvinylidene difluoride membrane. The membrane was incubated with a rabbit anti-rat TNF-alpha or rabbit anti-rat ICAM-1 (both 1:500) for $1 \mathrm{~h}$. After extensive washing, the membrane was incubated with a horseradish peroxidase (HRP)-conjugated goat-anti-rabbit IgG (1:1000; Bosider, Wuhan, China) prior to ECL visualization (Pierce Corporation). Optical density of the band at appropriate molecular weight was used to estimate the amount of protein. Experiments were repeated 3 times independently.

\section{Blood biochemical analysis}

Serum homocysteine concentration was measured using a HPLC method as described previously ${ }^{[23]}$. Blood endothelin concentration was measured using a radioimmunoassay (RIA Institute of People's Liberation Army General Hospital Science and Technology Development Center) ${ }^{[24]}$. Serum NO concentration was measured using a kit from Nanjing Jiancheng Bioengineering Research Institute (Nanjing, China) ${ }^{[24]}$.

\section{Statistical analysis}

Data are expressed as mean \pm SD. Statistical analysis was performed with one-way ANOVA followed by least-significant difference $t$-test for post hoc comparison. Statistical significance was set at $P<0.05$.

\section{Results}

In contrast to the normal appearances in the blank control rats, the intima of descending aorta in rats receiving methioninerich diet was thickened, and contained scattered foam cells (Figure 1). Danshensu treatment, either simultaneous with methionine-rich diet or afterwards, significantly decreased the number of foam cells.

\section{Effect of danshensu on homocysteine level}

Methionine-rich diet significantly increased serum homocysteine concentration $(P<0.01$ vs blank controls; Figure 2). Such an increased homocysteine was significantly attenuated by treatment with folate-VitB6-VitB12 vitamin and danshensu after the 3-month methionine-rich diet $(P<0.01$ and $<0.05$ 


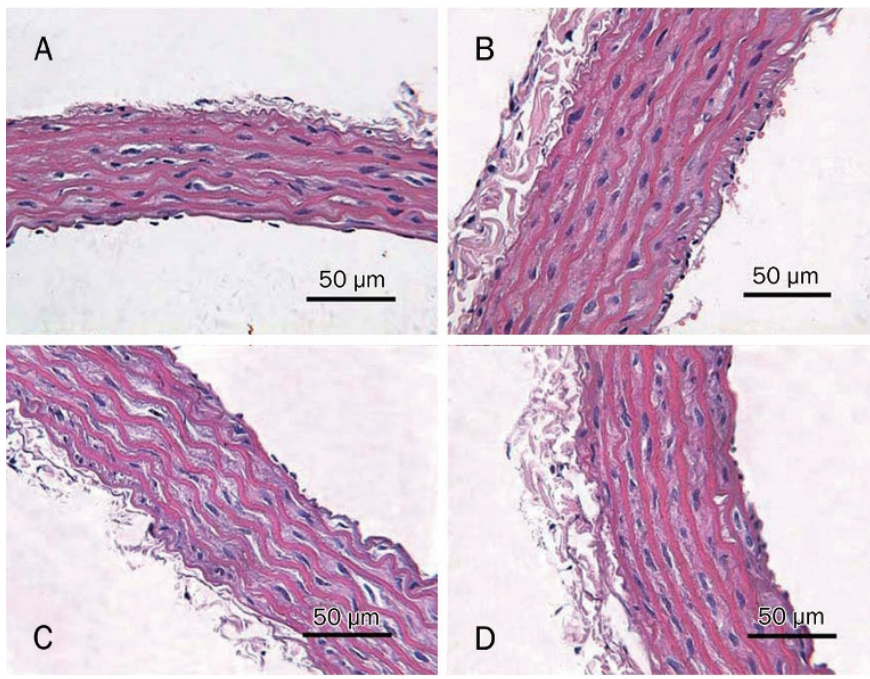

Figure 1. Morphology of aortic wall was observed by light microscopy. (A) blank controls; (B) model group; (C) "preventive" group; (D) danshensu group.

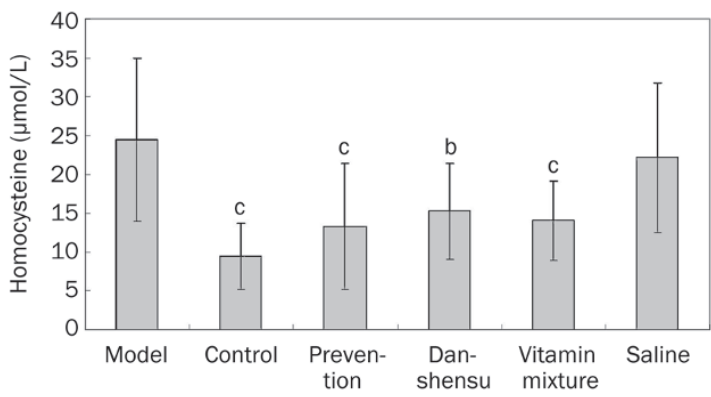

Figure 2. Serum homocysteine concentration in different groups. ${ }^{\mathrm{b}} P<0.05,{ }^{\mathrm{C}} P<0.01$ vs model group.

respectively). Preventive treatment (daily danshensu during the 3-month methionine-rich diet) also significantly decreased serum homocysteine level $(P<0.01$ vs the "model" group).

\section{Effect of danshensu on blood endothelin and NO}

Methionine-rich diet significantly increased plasma endothelin concentration $(P<0.01$ vs blank controls; Figure 3). Such

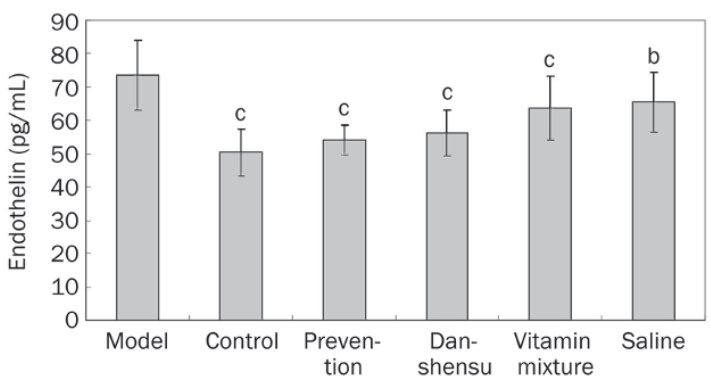

Figure 3. Plasma endothelin levels in different groups. ${ }^{b} P<0.05,{ }^{c} P<0.01$ vs model group. a response was significantly attenuated by treatment with vitamin mixture and danshensu ( $P<0.01$ for both). Preventive danshensu treatment also significantly decreased endothelin concentration. Saline treatment also produced a statistically significant reduction in endothelin concentration in rats exposed to methionine-rich diet $(P<0.05)$.

Serum NO level was significantly decreased by methioninerich diet $(P<0.01$ vs blank controls; Figure 4$)$. Treatment with danshensu, either after or simultaneously with methioninerich diet, significantly increased serum NO level $(P<0.05$ and $<0.01$, respectively). Treatment with vitamin mixture produced a trend of increasing serum NO, but the difference was not statistically significant.

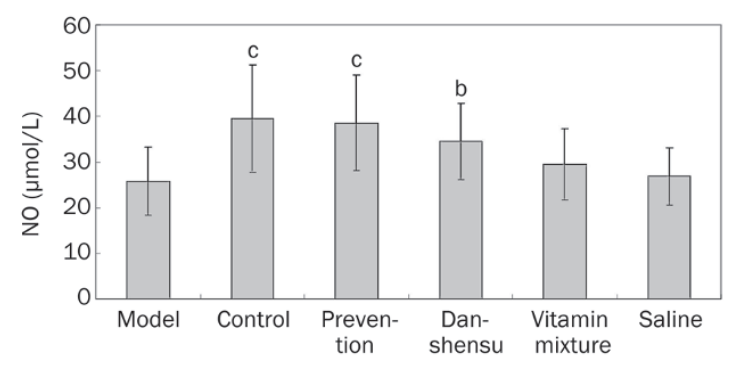

Figure 4. Serum NO concentration in different groups. ${ }^{b} P<0.05,{ }^{\mathrm{c}} P<0.01$ vs model group.

Effect of danshensu on TNF-alpha and ICAM-1

Immunohistochemical analysis revealed dramatically increased expression of TNF-alpha (Figure 5A) and ICAM-1 (Figure 6A) in endothelial cells in response to methionine-rich diet. Increased expression of TNF-alpha and ICAM-1 was significantly attenuated by vitamin mixture and danshensu treatment, regardless of the treatment timing $(P<0.01$ for all). Results obtained from Western blot analysis (Figure 5B and $6 \mathrm{~B})$ were largely consistent with the immunohistochemical findings.

\section{Discussion}

Folate, vitamin B6 and vitamin B12 are key cofactors to the enzymes that metabolize homocysteine, and have been used to manage hyperhomocysteinemia ${ }^{[25]}$. Hyperhomocysteinemia is associated with increased risk of thrombotic and atherosclerotic vascular diseases ${ }^{[25]}$. Elevated level of homocysteine causes lipid peroxidation, inflammatory reactions, and vascular endothelial injury ${ }^{[26]}$. In the current study, danshensu treatment significantly lowered the serum homocysteine concentration in rats receiving a methionine-rich diet. The magnitude of such an action was similar to that of a vitamin mixture containing folate, VitB6 and VitB12. Effects of danshensu were more robust when given simultaneous to methionine-rich diet, indicating the superiority of preventive treatment. We speculate that contributing factors to this phenomenon is the ability of danshensu to promote the catabolism ${ }^{[19]}$ and excretion of homocysteine during the period of methionine intake. 
A
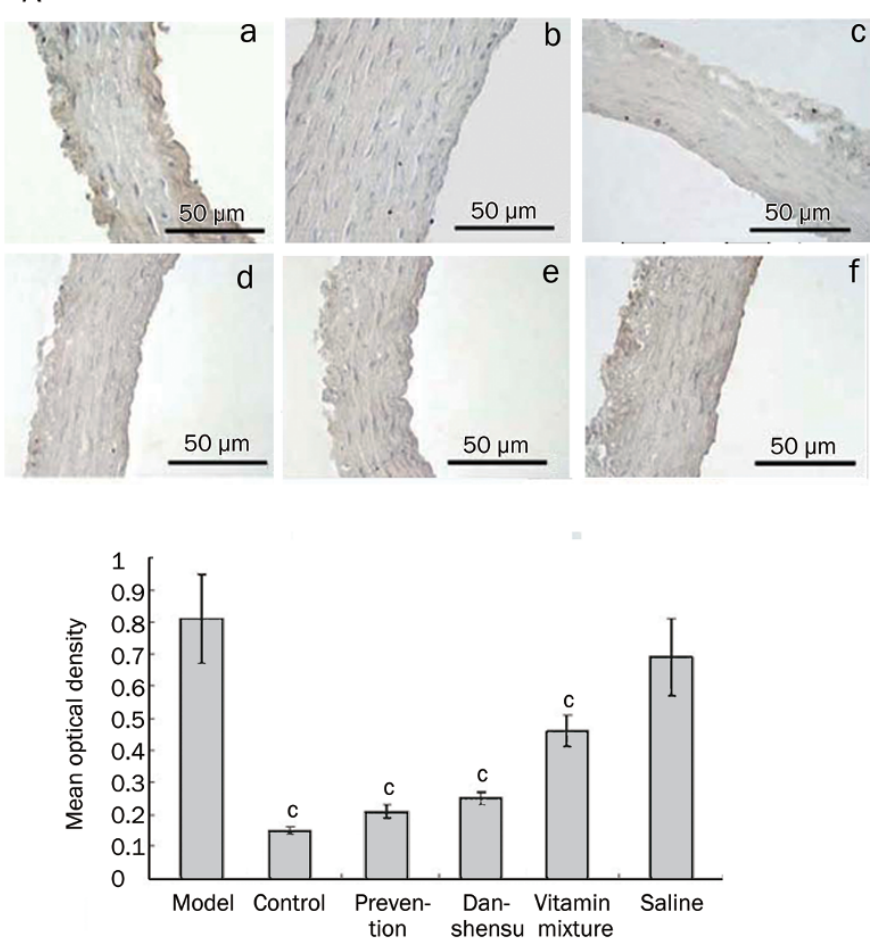

B
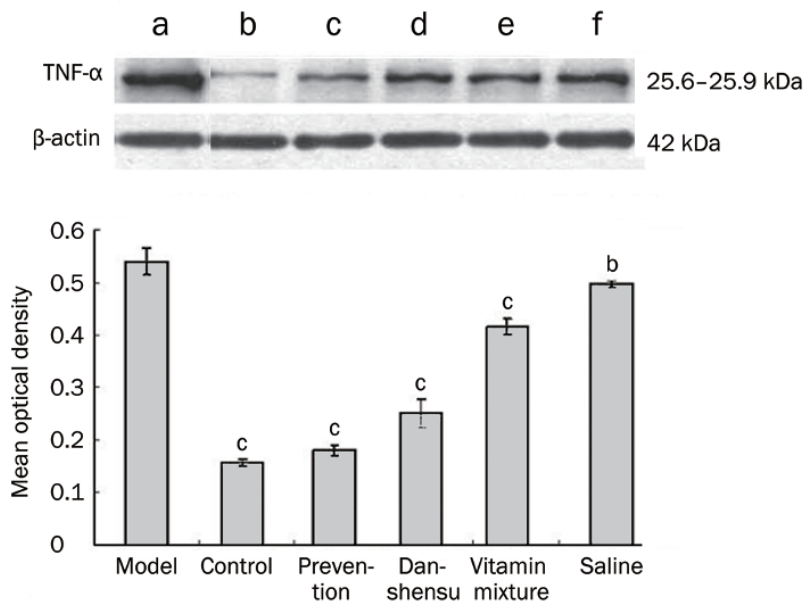

Figure 5. The effect of Danshensu on TNF- $\alpha$ expression in endothelium in a rat model of hyperhomocysteinemia. (A) TNF- $\alpha$ expression determined by immunohistochemistry. Upper: Representative photographs. Bottom: a statistical analysis of immunohistochemical results. ${ }^{\mathrm{C}} P<0.01 \mathrm{vs}$ model group. (B) TNF- $\alpha$ expression determined by Western blot. Upper: Representative photographs. Bottom: a statistical analysis of Western blot results. (a) model group; (b) blank controls; (c) prevention group; (d) danshensu group; (e) vitamin mixture group; (f) saline group. ${ }^{\mathrm{b}} P<0.05$, ${ }^{\mathrm{c}} P<0.01$ vs model group.

A major function of $\mathrm{NO}$ in the cardiovascular system is to relax both large arteries and small resistance vessels ${ }^{[26]}$. In contrast, endothelin induces vasoconstriction, participates in inflammation, cellular injury, and vascular events ${ }^{[27]}$. Con-
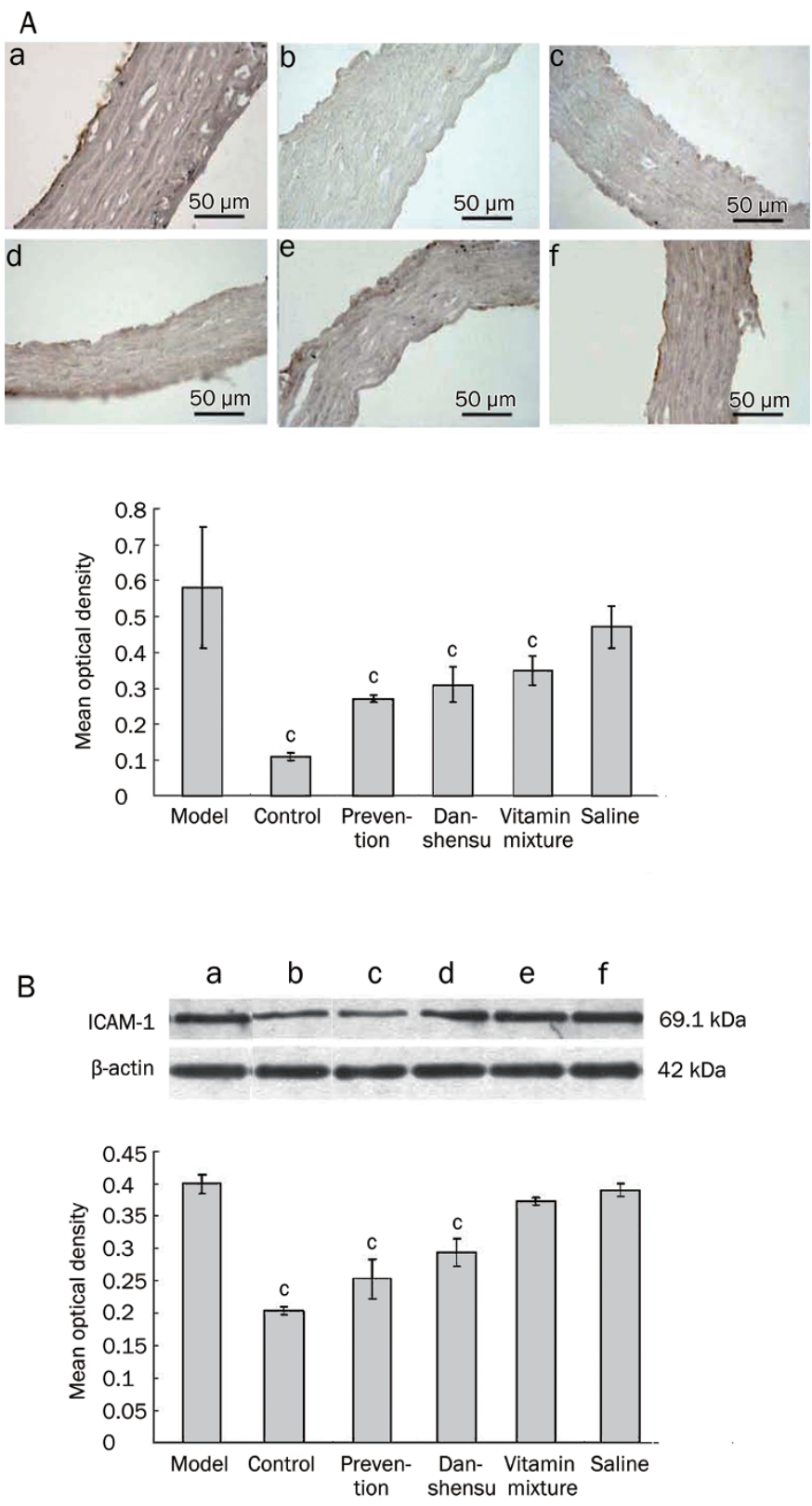

Figure 6. The effect of Danshensu on ICAM-1 expression in endothelium in a rat model of hyperhomocysteinemia. (A) ICAM-1 expression determined by immunohistochemistry. Upper: Representative photographs. Bottom: a statistical analysis of immunohistochemical results. ${ }^{\circ} P<0.01$ vs model group. (B) ICAM-1 expression determined by Western blot. Upper: Representative photographs. Bottom: a statistical analysis of Western blot results. (a) model group; (b) blank controls; (c) prevention group; (d) danshensu group; (e) vitamin mixture group; (f) saline group. ${ }^{\mathrm{c}} P<0.01 \mathrm{vs}$ model group.

sistent with previous studies ${ }^{[8,28-32]}$, our results indicated that $\mathrm{NO}$ is decreased upon hyperhomocysteinemia. In contrast, endothelin was significantly increased. These changes would result in increased vascular contraction, and might have contributed to the eventual development of atherosclerosis. Treatment with danshensu clearly attenuated the changes of NO 
and endothelin in response to methionine-rich diet, suggesting that the preventive/therapeutic effects of danshensu on atherosclerosis are at least partially mediated by vasodilation secondary to decreased level of serum homocysteine. In addition to indirect effect via decreased homocysteine level, danshensu has direct action on vascular endothelium. For example, a previous report ${ }^{[33]}$ indicated that danshensu could result in significant vasodilation through promoting the opening of nonselective potassium channels and small-conductance calciumsensitive potassium channels in vascular smooth muscle cells. In our experiments, the level of endothelin but not $\mathrm{NO}$ was significantly lower in rats receiving 3-month saline treatment after methionine-rich diet (saline group) in comparison to immediately after the methionine-rich diet ("model" group), indicating differential spontaneous recovery of various pathological changes after discontinuation of the methionine-rich diet.

A previous study demonstrated that hyperhomocysteinemia could increase inflammatory responses mediated by NF-kap$\mathrm{paB}$ and TNF-alpha via activating the ERK $(1 / 2) / \mathrm{p} 38 \mathrm{MAPK}$ pathway ${ }^{[10]}$. TNF-alpha is mainly secreted by monocytes and macrophages ${ }^{[34]}$. But under certain circumstances, TNF-alpha can also be secreted by endothelial cells, vascular smooth muscle cells, and cardiac fibroblast cells ${ }^{[35]}$. TNF-alpha could damage endothelial cells and vessel wall, and thus contribute to the formation of plaques ${ }^{[36]}$, possibly through stimulating the synthesis of matrix metalloproteinases-9 (MMP-9) by macrophage $^{[37,38]}$.

ICAM-1 is expressed constitutively at low levels by vascular endothelial cells under normal conditions, but expressed at large quantity upon stimulation by inflammatory cytokines such as TNF-alpha ${ }^{[39]}$. Increased ICAM-1 allows the attachment of leukocytes to the endothelium and subsequent migration into peripheral tissue ${ }^{[39]}$. Antioxidants can decrease TNFalpha synthesis/release by a variety of cell types and ICAM-1 expression by vascular endothelial cells ${ }^{[39]}$. Danshensu is a known antioxidant. Therefore, decreased TNF-alpha and ICAM-1 expression upon danshensu treatment could partially be attributed to its antioxidant property.

In our experiment, high level of TNF-alpha and ICAM-1 expression was observed in rats exposed to methionine-rich diet. Danshensu treatment, either simultaneous to methionine-rich diet or afterwards, significantly decreased TNF-alpha and ICAM- 1 expression. It remains to be investigated whether such effects are mediated by the ERK1/2/p38MAPK pathway as suggested by Bai et $a l^{[10]}$.

In summary, our findings demonstrated that danshensu could lower homocysteine level and attenuate atherosclerosis in rats receiving a methionine-rich diet. Signaling molecules that favor vasoconstriction, such as endothelin, were decreased by danshensu. Molecules that relax arteries, such as NO, were increased. Danshensu treatment also attenuated the overexpression of TNF-alpha and ICAM-1. Considering its excellent safety profile, we propose that danshensu could be used in people at high risk to develop atherosclerotic diseases.

\section{Acknowledgements}

This study was supported by the National Basic Research Program of China (national "973" Project, 2005CB523301) and grants from the National Natural Science Foundation of China (No. 30801503, 30772810, 30873325). Assistance was provided by the key laboratory of cardiovascular remodeling and function research and the Chinese Ministry of Education.

\section{Author contribution}

Yu-xia ZHAO and Yun-fang LIU designed this research project; Rui-xue YANG carried out the experiments, analyzed the data, and wrote the manuscript; Shan-ying HUANG, Fangfang YAN, Xiao-ting LU, Yi-fan XING, and Yan LIU contributed analytical tools and reagents; Yu-xia ZHAO revised the manuscript.

\section{References}

1 Guerzoni AR, Biselli PM, Godoy MF, Souza DR, Haddad R, Eberlin MN, et al. Homocysteine and MTHFR and VEGF gene polymorphisms: impact on coronary artery disease. Arq Bras Cardiol 2009; 92: 263-8.

2 Patrick A, O'Callaghan, Fitzgerald A, Fogarty J, Gaffney P, Hanbidge $M$, et al. New and old cardiovascular risk factors: C-reactive protein, homocysteine, cysteine and von Willebrand factor increase risk, especially in smokers. Eur J Cardiovasc Prev Rehabil 2005; 12: 542-7.

3 Vannucchi H, Melo SS. Hyperhomocysteinemia and cardiometabolic risk. Arq Bras Endocrinol Metabol 2009; 53: 540-9.

4 Perez-de-Arce K, Foncea R, Leighton F. Reactive oxygen species mediates homocysteine-induced mitochondrial biogenesis in human endothelial cells: modulation by antioxidants. Biochem Biophys Res Commun 2005; 338: 1103-9.

5 Qureshi I, Chen H, Brown AT, Fitzgerald R, Zhang X, Breckenridge J, et al. Homocysteine-induced vascular dysregulation is mediated by the NMDA receptor. Vasc Med 2005; 10: 215-23.

6 Chaava M, Bukia T, Shaburishvili T. Homocysteine as risk marker of cardiovascular disease. Georgian Med News 2005; 127: 65-70.

7 Fowler B. Homocystein - an independent risk factor for cardiovascular and thrombotic diseases. Ther Umsch 2005; 62: 641-6.

8 Murawska-clalowicz E, Januszewska L, Zuwala-jagiello J, Millczarska J, Zawadzki M, Paprocka-borowicz M, et al. Melatonin decreases homocysteine level in blood of rats. J Physiol Pharmacol 2008; 59: 717-29.

9 Postea O, Krotz F, Henger A, Keller C, Weiss N. Stereospecific and redox-sensitive increase in monocyte adhesion to endothelial cells by homocysteine. Arterioscler Thromb Vasc Biol 2006; 26: 508-13.

10 Bai YP, Liu YH, Chen J, Song T, You Y, Tang ZY, et al. Rosiglitazone attenuates NF-kappaB-dependent ICAM-1 and TNF-alpha production caused by homocysteine via inhibiting ERK1/2/p38MAPK activation. Biochem Biophys Res Commun 2007; 360: 20-6.

11 Bønaa KH, Njølstad I, Ueland PM, Schirmer H, Tverdal A, Steigen T, et al. Homocysteine lowering and cardiovascular events after acute myocardial infarction. N Engl J Med 2006; 354: 1578-88.

12 Lonn E, Yusuf S, Arnold MJ, Sheridan P, Pogue J, Micks M, et al. Homocysteine lowering with folic acid and B vitamins in vascular disease. N Engl J Med 2006; 354: 1567-77.

13 Toole JF, Malinow MR, Chambless LE, Spence JD, Pettigrew LC, Howard VJ, et al. Lowering homocysteine in patients with ischemic stroke to prevent recurrent stroke, myocardial infarction, and death: 
the Vitamin Intervention for Stroke Prevention (VISP) randomized controlled trial. JAMA 2004; 291: 565-75.

14 Cheng TO. Cardiovascular effects of danshen. Int J Cardiol 2007; 121: 9-22.

15 Wang F, Liu YY, Liu LY, Zeng QJ, Wang CS, Sun K, et al. The attenuation effect of 3,4-dihydroxy-phenyl lactic acid and salvianolic acid $B$ on venular thrombosis induced in rat mesentery by photochemical reaction. Clin Hemorheol Microcirc 2009; 42: 7-18.

16 Han JY, Horie Y, Fan JY, Sun K, Guo J, Miura S, et al. Potential of 3,4-dihydroxy-phenyl lactic acid for ameliorating ischemia-reperfusioninduced microvascular disturbance in rat mesentery. Am J Physiol Gastrointest Liver Physiol 2009; 296: 36-44.

17 Chan K, Chui SH, Wong DY, Ha WY, Chan CL, Wong RN. Protective effects of danshensu from the aqueous extract of Salvia miltiorrhiza (danshen) against homocysteine-induced endothelial dysfunction. Life Sci 2004; 75: 3157-71.

18 Yang GD, Zhang H, Lin R, Wang WR, Shi XL, Liu Y, et al. Downregulation of $\mathrm{CD} 40$ gene expression and inhibition of apoptosis with Danshensu in endothelial cells. Basic Clin Pharmacol Toxicol 2009; 104: 87-92.

19 Cao YG, Chai JG, Chen YC, Zhao J, Zhou J, Shao JP, et al. Beneficial effects of danshensu, an active component of Salvia miltiorrhiza, on homocysteine metabolism via the trans-sulphuration pathway in rats. Br J Pharmacol 2009; 157: 482-90.

20 Ding M, Zhao GR, Yuan YJ, Guo ZX. Aqueous extract of salvia miltiorrhoza regulates adhesion molecule expression of tumor necrosis factor $\alpha$-induced endothelial cells by blocking activation of nuclear factor kB. J Cardiovasc Pharmacol 2005; 45: 516-24.

21 Wu L, Li X, Li Y, Wang L, Tang Y, Xue M. Proliferative inhibition of danxiongfang and its active ingredients on rat vascular smooth muscle cell and protective effect on the VSMC damage induced by hydrogen peroxide. J Ethnopharmacol 2009; 126: 197-206.

22 Costa FA, Prianti MG, Silva TC, Silva SM, Guerra JL, Goto H. T cells, adhesion molecules and modulation of apoptosis in visceral leishmaniasis glomerulonephritis. BMC Infect Dis 2010; 10: 112.

23 Cole DE, Lehotay DC, Evrovski J. Simplified simultaneous assay of total plasma homocysteine and methionine by HPLC and pulsed integrated amperometry. Clin Chem 1998; 44: 188-90.

24 Chen Z, Li CS, Zhang J, Pang BS, Xia CQ, Liu XF. Relationship between endothelial dysfunction and serum homocysteine in patients with coronary lesions. Chin Med Sci J 2005; 20: 63-6.

25 Miyaki K. Genetic polymorphisms in homocysteine metabolism and response to folate intake: a comprehensive strategy to elucidate useful genetic information. J Epidemiol 2010; 20: 266-70.

26 Amin KA, Abd El-Twab TM. Oxidative markers, nitric oxide and homocysteine alteration in hypercholesterolimic rats: role of atorvastatine and cinnamon. Int J Clin Exp Med 2009; 2: 254-65.
27 Guan H, Wang P, Hui R, Edin ML, Zeldin DC, Wang DW. Adenoassociated virus-mediated human $\mathrm{C}$-reactive protein gene delivery causes endothelial dysfunction and hypertension in rats. Clin Chem 2009; 55: 274-84.

28 Molet S, Furukawa K, Maghazechi A, Hamid Q, Giaid A. Chemokineand cytokine-induced expression of endothelin 1 and endothelinconverting enzyme 1 in endothelial cells. J Allergy Clin Immunol 2000; 105: 333-8.

29 Er H, Evereklioglu C, Cumurcu T, Turkoz Y, Ozerol E, Sahin K, et al. Serum homocysteine level is increased and correlated with endothelin-1 and nitric oxide in Behçet's disease. $\mathrm{Br} J$ Ophthalmol 2002; 86: 653-7.

30 Duan J, Dai S, Fang CX, Sun R, Shavali S, Sharma SK, et al. Phytoestrogen alpha-zearalanol antagonizes homocysteine-induced imbalance of nitric oxide/endothelin-1 and apoptosis in human umbilical vein endothelial cells. Cell Biochem Biophys 2006; 45: 137-45.

31 de Valk-de Roo GW, Stehouwer CD, Lambert J, Schalkwijk CG, van der Mooren MJ, Kluft C, et al. Plasma Homocysteine is weakly correlated with plasma endothelin and von Willebrand factor but not with endothelium-dependent vasodilatation in healthy postmenopausal women. Clin Chem 1999; 45: 1200-5.

32 Sen U, Tyagi N, Kumar M, Moshal KS, Rodriguez WE, Tyagi SC. Cystathionine- $\beta$-synthase gene transfer and 3-deazaadenosine ameliorate inflammatory response in endothelial cells. Am J Physiol Cell Physiol 2007; 293: 1779-87.

33 Zhang N, Zou H, Jin L, Wang J, Zhong MF, Huang P, et al. Biphasic effects of sodium danshensu on vessel function in isolated rat aorta. Acta Pharmacol Sin 2010; 31: 421-8.

34 Mandal P, Pritchard MT, Nagy LE. Anti-inflammatory pathways and alcoholic liver disease: role of an adiponectin/interleukin-10/heme oxygenase-1 pathway. World J Gastroenterol 2010; 16: 1330-6.

35 Long AA. Monoclonal antibodies and other biologic agents in the treatment of asthma. MAbs 2009; 1: 237-46.

36 Rodriquez C, Alcudia JF, Martinez-Gonzalez J, Raposo B, Navarro MA, Badimon L. Lysyl oxidase (LOX) down-regulation by TNFalpha: a new mechanism underlying TNFalpha-induced endothelial dysfunction. Atherosclerosis 2008; 196: 558-64.

37 Rowsell S, Hawtin P, Minshull CA, Jepson H, Brockbank SM, Barratt DG, et al. Crystal structure of human MMP9 in complex with a reverse hydroxamate inhibitor. J Mol Biol 2002; 319: 173-8.

38 Chung KF. Cytokines in chronic obstructive pulmonary disease. Eur Respir J Suppl 2001; 34: 50-9.

39 Hubbard AK, Rothlein R. Intercellular adhesion molecule-1 (ICAM-1) expression and cell signaling cascades. Free Radic Biol Med 2000; 28: $1379-86$. 